\title{
Airway Resistance and Respiratory Compliance in Children with Acute Viral Bronchiolitis Requiring Mechanical Ventilation Support
}

\author{
Cinara Andreolio ${ }^{1}$, Jefferson P Piva ${ }^{2}$, Francisco Bruno ${ }^{3}$, Tais S da Rocha ${ }^{4}$, Pedro CR Garcia ${ }^{5}$
}

\begin{abstract}
Background: Acute viral bronchiolitis (AVB) is a very frequent disease that affects the lower airways of young children increasing the inspiratory and expiratory resistance in variable degree as well as reducing the pulmonary compliance. It would be desirable to know whether these variables are associated with the outcome.

Objectives: To evaluate the respiratory mechanics in infants with AVB requiring mechanical ventilation (MV) support and to evaluate if respiratory mechanics predict outcomes in children with AVB supported on MV. To evaluate the respiratory mechanics in infants with AVB submitted to MV. Materials and methods: A prospective observational study was conducted in two pediatric intensive care units (PICUs) between February 2016 and March 2017. Included were infants (1 month to 1 year old) admitted with AVB and requiring MV for $>48$ hours. Auto-PEEP, dynamic compliance (Cdyn), static compliance (Cstat), expiratory resistance (ExRes), and inspiratory resistance (InRes) were evaluated once daily on the second and third day of MV.

Results: A total of 64 infants (median age of 2.8 months and a mean weight of $4.8 \pm 1.7 \mathrm{~kg}$ ) were evaluated. A mean positive inspiratory pressure (PIP) of $31.5 \pm 5.2 \mathrm{cmH}_{2} \mathrm{O}$, positive end-expiratory pressure (PEEP) of $5.5 \pm 1.4 \mathrm{cmH}_{2} \mathrm{O}$, resulting in a mean airway pressure (MAP) of $12.5 \pm 2.2$ $\mathrm{cmH}_{2} \mathrm{O}$ and delta pressure of $22.5 \pm 4.4 \mathrm{cmH}_{2} \mathrm{O}$ without difference between the two hospitals. Measurements of respiratory mechanics showed high values of InRes and ExRes (median 142 [IQ $\left.{ }_{25-75} 106-180\right] \mathrm{cmH}_{2} \mathrm{O} / \mathrm{L} / \mathrm{s}$ and $158\left[\mathrm{IQ}_{25-75} 130-195.3\right] \mathrm{cmH}_{2} \mathrm{O} / \mathrm{L} / \mathrm{s}$, respectively), accompanied by decreased Cdyn and Cstat $\left(0.46 \pm 0.19\right.$ and $0.81 \pm 0.25 \mathrm{~mL} / \mathrm{kg} / \mathrm{cmH}_{2} \mathrm{O}$, respectively). None of the variables was associated with mortality, length of MV, or length of PICU stay.

Conclusion: Infants with AVB requiring MV support present very high InRes and ExRes values. These findings might be the reason for the aggressive ventilatory parameters, especially PIP, required to ventilate this group of children with lower airway obstruction.

Clinical significance: Monitoring respiratory mechanics could represent a useful tool to guide the ventilatory strategy to be adopted in patients with AVB.

Keywords: Airway resistance, Lung compliance, Mechanical ventilation, Pediatrics, Viral bronchiolitis.

Indian Journal of Critical Care Medicine (2021): 10.5005/jp-journals-10071-23594
\end{abstract}

\section{INTRODUCTION}

Acute viral bronchiolitis (AVB) is a self-limiting respiratory disease with a seasonal pattern that compromises the lower airways, with high prevalence among young children ( $<2$ years old $).^{1-3}$ It is estimated that $2-3 \%$ of infants with AVB are hospitalized, of which $5-15 \%$ are admitted to a pediatric intensive care unit (PICU) and of which $1-15 \%$ will require mechanical ventilation (MV) support. ${ }^{4-6}$

The mortality of children with AVB on MV has been dramatically reduced to $<5 \% .{ }^{5-8}$ The actual challenges in this situation are related to reducing morbidity, especially from ventilator-induced lesions, and a better understanding of ventilation strategies to be adopted in the most severe cases.

It has been suggested that evaluating respiratory mechanics parameters, based on curves, graphs, and absolute values, could guide and help MV support in the different groups of respiratory diseases. ${ }^{9-12}$ The curves presented on many ventilators aid in the interpretation of pathophysiological changes in relation to MV variables (pressures, volume, and flow). ${ }^{11-14}$ Most ventilators allow the assessment of static (Cstat) and dynamic (Cdyn) compliance, inspiratory and expiratory resistance (InRes and ExRes), elastance, auto-PEEP, and respiratory work, but their measurement is not routinely performed in the PICU., ${ }^{9,10,12-14}$

\begin{abstract}
${ }^{1-4}$ Pediatric Intensive Care Unit, Hospital de Clinicas de Porto Alegre, Porto Alegre, Rio Grande Do Sul, Brazil; UFRGS University, Rio Grande Do Sul, Brazil

${ }^{5}$ Pediatric Intensive Care Unit, Pontificia Universidade Católica Do Rio Grande Do Sul, Porto Alegre, Rio Grande Do Sul, Brazil

Corresponding Author: Cinara Andreolio, Pediatric Intensive Care Unit, Hospital de Clinicas de Porto Alegre, Porto Alegre, Rio Grande Do Sul, Brazil; UFRGS University, Rio Grande Do Sul, Brazil, Phone:
\end{abstract} +5551998061036, e-mail: candreolio@hcpa.edu.br

How to cite this article: Andreolio C, Piva JP, Bruno F, da Rocha TS, Garcia PCR. Airway Resistance and Respiratory Compliance in Children with Acute Viral Bronchiolitis Requiring Mechanical Ventilation Support. Indian J Crit Care Med 2021;25(1):88-93.

Source of support: Nil

Conflict of interest: None

There are several studies describing the supportive treatment for patients with severe AVB. ${ }^{4-6}$ However, there is little literature on the values of respiratory mechanics variables (e.g., compliance

()The Author(s). 2021 Open Access This article is distributed under the terms of the Creative Commons Attribution 4.0International License (https://creativecommons. org/licenses/by-nc/4.0/), which permits unrestricted use, distribution, and non-commercial reproduction in any medium, provided you give appropriate credit to the original author(s) and the source, provide a link to the Creative Commons license, and indicate if changes were made. The Creative Commons Public Domain Dedication waiver (http://creativecommons.org/publicdomain/zero/1.0/) applies to the data made available in this article, unless otherwise stated. 
and resistance $)^{14-19}$ and the respective ventilation strategies to be adopted in these situations. ${ }^{4,6,20-23}$

The most important pathophysiological change in AVB is smallairway obstruction, caused by peribronchial infiltrate, interstitial edema, epithelial desquamation, and inflammatory infiltrate. These changes lead to increased inspiratory and expiratory resistance, resulting in increased respiratory work, air trapping (auto-PEEP), increased functional residual capacity (FRC), decreased pulmonary compliance, and hypoxemia. There is also alveolar collapse (atelectasis) with increased dead space and pulmonary shunt. Both, air trapping and atelectasis decrease lung compliance., ${ }^{1,15,16,21,22}$

The heterogeneity of this disease makes ventilation of these infants a challenge as many have more resistance behavior while others develop compliance changes progressing to acute respiratory distress syndrome (ARDS). Therefore, measuring respiratory mechanics in these patients is essential to identify the appropriate ventilatory strategy. To date, there are few pediatric studies reporting values of resistance, compliance, and auto-PEEP in children with severe AVB. ${ }^{15-19}$ Cruces et al. in a similar study described low values for inspiratory and expiratory resistance, emphasizing that "these findings may seem unexpected and contradictory with the current understanding of severe bronchiolitis as a primarily obstructive airway disease with an increase in expiratory resistance...." In our daily practice when ventilation children with $A V B$, we frequently observed higher values for respiratory resistance. Based on this diversity of findings, we pondered that it would be desirable to obtain more data in this regard to identify the range and the degree of airway compromise in this population.

Our objective was to describe some respiratory mechanics variables (namely Cstat and Cdyn, InRes, ExRes, and auto-PEEP) in infants in the acute phase of severe AVB submitted to MV and evaluating its possible association with the outcome.

\section{Materials and Methods}

\section{Study Design and Population}

A prospective observational study was carried out in two Brazilian PICUs located in highly complex university hospitals: Hospital de Clínicas de Porto Alegre (HCPA) and Hospital São Lucas da PUCRS. These two units, with 13 beds each, have a similar profile, involved in the care of clinical and surgical patients, with similar routines and MV strategies. The Ethics and Research Committees of both institutions approved the study, requiring the parents or guardians to sign an informed consent form.

\section{Data Collection}

Between February 1, 2016 and March 31, 2017, infants (30 days to 1 year old) admitted to the two PICUs with clinical diagnosis of AVB and likely requiring $\mathrm{MV}$ support for $>48$ hours were included in the study. The following inclusion criteria were required: $:^{1-3}$

- Presence of the classic symptoms of acute viral illness (tachypnea, respiratory distress, runny nose, cough, moaning, fever, nasal flaring).

- Chest radiograph showing typical signs of pulmonary hyperinflation (flattening of the diaphragms, thoracic ribs rectification, and increased intercostal space), associated or not with areas of consolidation or subsegmental atelectasis and variable bronchoalveolar infiltrate.

- Viral screening test was mandatory, but, its positivity was not obligatory.

\section{Exclusion Criteria}

Infants with severe thoracic deformity, previous pneumonectomy, presence of intrathoracic tumors, cardiovascular instability characterized by hypotension or arrhythmia in the planned period for measurements, uncorrected congenital heart disease, concomitant chronic lung disease, tracheostomy device, chest, or mediastinal drains. An air leak around the tracheal tube $>15 \%$ [(inspiratory tidal volume-expiratory tidal volume/inspiratory tidal volume) $\times 100$ ] was an exclusion criterion. ${ }^{24}$

To standardize the measurements, we have decided to evaluate these variables after the morning rounds on the second and third day of MV (assuming it as the acute phase of the disease). The measurements were not performed on the first day of MV because of the adjustments that are usually required in the first 24 hours of MV support. Anthropometric and clinical variables, such as age, weight, gender, mortality, type of virus, ventilatory mode, and the cumulative fluid overload, were recorded. The outcome variables like mortality, air leak, MV time, and days in ICU were recorded.

Mechanical ventilation support was provided with the same equipment in both hospitals (SERVO i-Maquet ${ }^{\circledR}$ ). The SIMV with PS (synchronous intermittent mandatory ventilation with pressure support) was used for MV support in these children. ${ }^{11,13,19,21}$ The protocol to ventilate AVB adopted in both institutions is based on: Low respiratory rate (RR) ( $<20$ breaths/minute), inspiratory time between 0.75 and 0.9 seconds, a target tidal volume between 8 and $10 \mathrm{~mL} / \mathrm{kg}$, positive end-expiratory pressure (PEEP) of $5 \mathrm{cmH}_{2} \mathrm{O}$, and an $\mathrm{FiO}_{2}$ equal or lower than $40 \%$ to obtain an saturation close to $90 \%$.

Adjunct therapy, such as bronchodilators, hypertonic nebulization, or mucolytic drugs are not used to treat AVB in both institutions.

Measurements of respiratory mechanics were recorded directly in the ventilator. The first measurement recorded was the Cdyn, which is measured continuously on the ventilator and does not require inspiratory pause. ${ }^{13}$ Next, the other measurements, which required the absence of spontaneous ventilation, were performed. ${ }^{11-13}$ Before the measurements, the infant received a dose of rocuronium $(0.5$ $\mathrm{mg} / \mathrm{kg}$ ) and MV support was shifted to controlled-volume mode $(\mathrm{CV})$, respecting the same tidal volume, respiratory rate, $\mathrm{FiO}_{2}$, and PEEP. During the inspiratory pause, Cstat, elastance, and InRes were measured. Auto-PEEP and ExRes were determined after an expiratory pause. Auto-PEEP is the resultant value of PEEPtot observed subtracted from the external PEEP imposed to the patient. ${ }^{13}$ Subsequently, the delta pressure $(\Delta \mathrm{P})$ was calculated by subtracting PEEPtot from the positive inspiratory pressure (PIP). ${ }^{25-28}$

In case the patient was submitted to any distressful procedure (e.g., tracheal tube aspiration, respiratory physiotherapy, chest X-ray, or changing positioning from prone to supine), there was a delay of 1 hour before performing the measurements. ${ }^{23-25}$ If there was a decrease in oxygen saturation or any hemodynamic instability, the measurements were immediately suspended, returning to the previous MV mode support.

Demographic variables, vital signs, and the patient's position (supine or prone) were recorded at the time of measurements. The outcomes evaluated in this study were length on MV (days), length of ICU stay, length of hospital stay, and death.

\section{Statistical Analysis}

The values obtained were recorded in a spreadsheet created for this purpose in Microsoft Excel and SPSS version 17 (Chicago, Illinois, USA). 
Continuous quantitative variables were expressed as mean and standard deviation or median and 25 to $75 \%$ interquartile range (IQ), for those variables without normal distribution. Categorical variables were described as absolute and relative values. The groups were compared using the Student $t$-test for independent samples, Mann-Whitney $U$ test for continuous variables. The level of significance was set at $p<0.05$. The association between variables was analyzed using the Pearson (parametric variables) and Spearman (non-parametric variables) correlation. The qualitative strength of the correlation between two variables was assessed according to the following classification: Linear correlation $(r)=$ 0 , zero strength; $r>0$ to 0.3 , weak strength; $r>0.3$ to 0.6 , regular strength; $r>0.6$ to 0.9 , strong strength; $r>0.9$ to 1 , very strong strength and; $r=1$, perfect strength. ${ }^{29}$ Statistical analysis was performed by SPSS version 17.

\section{Results}

To the PICU in hospital \#1, 640 patients were admitted where 268 required MV support. Forty-three patients were identified with AVB and eight patients were excluded based on the exclusion criteria. In hospital \#2, 523 patients were admitted to the PICU and 211 required MV support. In this group, 32 children were identified with AVB required MV support, being excluded 3 cases based on the exclusion criteria.

The study included 64 children with severe AVB in two PICUs, who were submitted to MV and required MV support longer than 48 hours.

Considering the characteristics evaluated, there were no significant differences between the two hospitals, except for the length of PICU stay, which was longer in hospital 2 (9 vs 12 days). There was no report of any adverse event (e.g., air leak) associated with the intervention, and no deaths were observed in this sample (Table 1).

The patients had a mean weight of $4.8 \pm 1.7 \mathrm{~kg}$, median age of $2.8\left[\mathrm{IQ}_{25-75}\right.$ 1.6-4.2] months, length of $\mathrm{MV}$ of $7\left[\mathrm{IQ}_{25-75} 6-9\right]$ days, and length of ICU stay of $10\left[\mathrm{IQ}_{25-75} 8-14\right]$ days. The virus was identified in $56 \%$ of cases, where respiratory syncytial virus (RSV) was the most common viral agent (65\%) (Table 1).

In $51.6 \%$ of patients, sedation and analgesia were performed combined with continuous infusion of opioids (morphine or fentanyl) and benzodiazepine (midazolam).

Table 1: General characteristics of sample, stratified by the hospitals

\begin{tabular}{lllll}
\hline & General & Hospital 1 & Hospital 2 & \\
\cline { 2 - 4 } Characteristics & $n=64$ & $n=35$ & $n=29$ & p value \\
\hline Sex & & & & \\
$\quad$ Male, $n(\%)$ & $38(60)$ & $22(63)$ & $17(59)$ & 0.61 \\
Age (months) & $2.8[1.6-4.2]$ & $2.4[1.6-3.7]$ & $2.9[1.7-4.4]$ & 0.54 \\
Weight (kg) & $4.8 \pm 1.7$ & $4.7 \pm 1.2$ & $4.8 \pm 2.2$ & 0.85 \\
ICU stay (days) & $10[8-14]$ & $9[7-12]$ & $12[9-16.5]$ & 0.019 \\
MV time (days) & $7[6-9]$ & $7[6-9]$ & $8[6-11]$ & 0.17 \\
Virus (\%) & & & & \\
$\quad$ Positive, $n$ (\%) & $36(56)$ & $20(57)$ & $16(55)$ & 0.22 \\
\hline
\end{tabular}

$\mathrm{ICU}$, intensive care unit; $\mathrm{MV}$, mechanical ventilation

Results of parametric variables were expressed as mean and standard deviation, and comparisons made using the Student $t$-test. Non-parametric variables were expressed as the median and $25-75 \%$ interquartile and compared using the Mann-Whitney $U$ test
We observed that $51.7 \%$ of patients used an endotracheal tube (ETT) with cuff. In 92.5\%, the ETT diameter used was $\leq 4 \mathrm{~mm}$.

The vital signs at the two moments of measurements did not differ, nor between the two hospitals, so we grouped the data assuming as a single sample. During the interventions, we found a mean heart rate $(H R)$ of $159.4 \pm 20.4$ beats/minute, a mean blood pressure of $64.8 \pm 15.8 \mathrm{~mm} \mathrm{Hg}$, a mean oxygen saturation of $97.4 \pm$ $2.5 \%$, and a median cumulative fluid balance (24 hours) of $25\left[\mathrm{IQ}_{25-75}\right.$ $11-42.5] \mathrm{mL} / \mathrm{kg}$, without any difference between the hospitals or days of measurement.

In the 2 days of measurements, it was observed that the two PICUs followed the same MV strategy with a mean RR of $19.5 \pm 2.4$ breaths/minute, PIP of $31.5 \pm 5.2 \mathrm{cmH}_{2} \mathrm{O}$, PEEP of $5.5 \pm 1.4 \mathrm{cmH}_{2} \mathrm{O}$, $\mathrm{FiO}_{2}$ of $0.3 \pm 0.08 \%$, expiratory tidal volume of $10.7 \pm 2.7 \mathrm{~mL} / \mathrm{kg}$, mean airway pressure (MAP) of $12.5 \pm 2.2 \mathrm{cmH}_{2} \mathrm{O}$, and $\Delta \mathrm{P}$ of $22.5 \pm$ $4.4 \mathrm{cmH}_{2} \mathrm{O}$, without any difference between the hospitals (Table 2).

While analyzing the pulmonary mechanics in patients with AVB subjected to MV, we did not observe any differences between the first and second day of measurement, nor between the two hospitals, so we chose to group the data totalizing 128 measurements (Table 3).

Table 3 shows the respiratory mechanics measurements observed in this group of infants with severe AVB subjected to MV. Attention is drawn to the high InRes and ExRes values, with a median of 142 [ $\left.\mathrm{IQ}_{25-75} 106-180\right]$ and 158 [ $\left.\mathrm{IQ}_{25-75} 130-195.3\right]$ $\mathrm{cmH}_{2} \mathrm{O} / \mathrm{L} / \mathrm{s}$, respectively. Even in the presence of high resistance of the lower airways, a low median auto-PEEP $\left(3\left[\mathrm{IQ}_{25-75} 2-5\right]\right) \mathrm{cmH}_{2} \mathrm{O}$ was observed, with difference between the two units (4 vs 2.5 $\left.\mathrm{cmH}_{2} \mathrm{O} ; p=0.018\right)$.

Table 2: MV parameters of patients in two hospitals, days 1 and 2

\begin{tabular}{|c|c|c|c|c|}
\hline Parameters & General & Hospital 1 & Hospital 2 & $p$ value \\
\hline $\mathrm{PIP} \mathrm{cmH}_{2} \mathrm{O}$ & $31.5 \pm 5.2$ & & & \\
\hline Day 1 & & $32 \pm 4.7$ & $31.5 \pm 6$ & 0.71 \\
\hline Day 2 & & $31.3 \pm 4.8$ & $31.3 \pm 5.7$ & 0.98 \\
\hline PEEP $\mathrm{cmH}_{2} \mathrm{O}$ & $5.5 \pm 1.4$ & & & \\
\hline Day 1 & & $5.5 \pm 1.0$ & $5.4 \pm 1$ & 0.87 \\
\hline Day 2 & & $5.3 \pm 1.2$ & $5.8 \pm 2.2$ & 0.36 \\
\hline $\mathrm{FiO}_{2}(\%)$ & $0.3 \pm 0.08$ & & & \\
\hline Day 1 & & $0.3 \pm 0.1$ & $0.35 \pm 0.1$ & 0.17 \\
\hline Day 2 & & $0.3 \pm 0.1$ & $0.32 \pm 0.1$ & 0.01 \\
\hline RR breaths/min & $19.5 \pm 2.4$ & & & \\
\hline Day 1 & & $19.1 \pm 1.9$ & $19.5 \pm 1.9$ & 0.2 \\
\hline Day 2 & & $18.4 \pm 2.1$ & $18.6 \pm 2.3$ & 0.19 \\
\hline $\mathrm{TV} \mathrm{mL} / \mathrm{kg}$ & $10.7 \pm 2.7$ & & & \\
\hline Day 1 & & $10.1 \pm 1.8$ & $10.8 \pm 2.2$ & 0.14 \\
\hline Day 2 & & $10.1 \pm 1.6$ & $10.9 \pm 2.6$ & 0.15 \\
\hline MAP $\mathrm{cmH}_{2} \mathrm{O}$ & $12.5 \pm 2.2$ & & & \\
\hline Day 1 & & $12.9 \pm 2.3$ & $12.2 \pm 2.2$ & 0.21 \\
\hline Day 2 & & $12.3 \pm 1.9$ & $12.3 \pm 2.3$ & 0.96 \\
\hline \multicolumn{5}{|c|}{$\Delta$ Pressure $\mathrm{cmH}_{2} \mathrm{O}$} \\
\hline Day 1 & $22.5 \pm$ & $22.5 \pm 4.2$ & $22.9 \pm 4.5$ & 0.69 \\
\hline Day 2 & 4.4 & $22 \pm 3.8$ & $22.4 \pm 5.4$ & 0.77 \\
\hline
\end{tabular}

PIP, positive inspiratory pressure; PEEP, positive end-expiratory pressure; $\mathrm{FiO}_{2}$ inspired oxygen fraction; $\mathrm{RR}$, respiratory rate; TV, tidal volume; MAP, mean airway pressure; $\Delta$ pressure, delta pressure

Results of parametric variables were expressed as mean and standard deviation, and comparisons made using the Student $t$-test 
Table 3: Measurements of respiratory mechanics observed in the two hospitals

\begin{tabular}{|c|c|c|c|c|}
\hline Measurements & $\begin{array}{l}\text { General } n \\
\text { measurements }=128\end{array}$ & $\begin{array}{l}\text { Hospital } 1 n \\
\text { measurements }=70\end{array}$ & $\begin{array}{l}\text { Hospital } 2 n \\
\text { measurements }=58\end{array}$ & $p$ value \\
\hline Cdyn mL/kg/cmH $\mathrm{cm}_{2} \mathrm{O}$ & $0.46 \pm 0.19$ & $0.46 \pm 0.16$ & $0.46 \pm 0.23$ & 0.86 \\
\hline Cstat $\mathrm{mL} / \mathrm{kg} / \mathrm{cmH}_{2} \mathrm{O}$ & $0.81 \pm 0.27$ & $0.8 \pm 0.25$ & $0.83 \pm 0.29$ & 0.55 \\
\hline InRes $\mathrm{cmH}_{2} \mathrm{O} / \mathrm{L} / \mathrm{s}$ & 142 [106-180] & $155.5[121.2-185.5]$ & $128.5[100-176.2]$ & 0.44 \\
\hline ExRes $\mathrm{cmH}_{2} \mathrm{O} / \mathrm{L} / \mathrm{s}$ & 158 [130-195.3] & 165 [135.2-210.7] & 147 [11.1-177.2] & 0.19 \\
\hline Auto-PEEP $\mathrm{cmH}_{2} \mathrm{O}$ & $3[2-5]$ & $4[2-5]$ & $2.5[1-4.7]$ & 0.018 \\
\hline
\end{tabular}

Cdyn, dynamic compliance; Cstat, static compliance; InRes, inspiratory resistance; ExRes, expiratory resistance

Results of parametric variables were expressed as mean and standard deviation, and comparisons made using the Student $t$-test

Results of non-parametric variables were expressed as median and $25-75 \%$ interquartile range, and comparisons made using the MannWhitney $U$ test

Table 4: Values of compliance and resistance in infants with uncompromised lungs, reported in the literature

\begin{tabular}{lcll}
\hline Normal lungs & $\mathrm{Crs} \mathrm{mL} / \mathrm{cmH}_{2} \mathrm{O} / \mathrm{kg}$ & Cstat $_{\mathrm{mL} / \mathrm{cmH}_{2} \mathrm{O}}$ & $\mathrm{Rrs} \mathrm{CmH}_{2} \mathrm{O} / \mathrm{L} / \mathrm{s}$ \\
\hline Hammer $^{16}$ & $1 \pm 0.04$ & & $60 \pm 0.01$ \\
Derish $^{15}$ & $0.99 \pm 0.26$ & & $33 \pm 19$ \\
Cid $^{14}$ & & $5-15$ (NB-1 year) & $40-15$ (NB-1 year) \\
Heilitt $^{19}$ & 0.6 & & 50 \\
\hline
\end{tabular}

Crs, respiratory system compliance; Cstat, static compliance; Rrs, respiratory system resistance

Table 5: Values of compliance and resistance in infants with acute viral bronchiolitis, reported in the literature and in this study

\begin{tabular}{|c|c|c|c|c|c|c|}
\hline$B V A$ & $\mathrm{Crs} \mathrm{mL} / \mathrm{cmH}_{2} \mathrm{O} / \mathrm{kg}$ & $\begin{array}{l}\text { Cdyn } \mathrm{mL} / \mathrm{kg} / \\
\mathrm{CmH}_{2} \mathrm{O}\end{array}$ & $\begin{array}{l}\text { Cstat } \mathrm{mL} / \mathrm{kg} / \\
\mathrm{CmH}_{2} \mathrm{O}\end{array}$ & $\mathrm{Rrs} \mathrm{CmH}_{2} \mathrm{O} / \mathrm{L} / \mathrm{s}$ & InRes $\mathrm{cmH}_{2} \mathrm{O} / \mathrm{L} / \mathrm{s}$ & ExRes $\mathrm{cmH}_{2} \mathrm{O} / \mathrm{L} / \mathrm{s}$ \\
\hline Hammer $^{16}$ & $0.57 \pm 0.04$ & & & $370 \pm 0.05$ & & \\
\hline Derish $^{15}$ & $0.56 \pm 0.15$ & & & $125 \pm 80.9$ & & \\
\hline Cruces $^{18}$ & $0.55[0.44-0.89]$ & & & & $38.8[32-53]$ & $40.5[22-55]$ \\
\hline Heilitt ${ }^{19}$ & 0.3 & & & 600 & & \\
\hline Almeida-Júnior ${ }^{17}$ & & & & $128.5[39.3-282.9]$ & & \\
\hline Andreolio & & $0.46 \pm 0.19$ & $0.81 \pm 0.27$ & & 142 [106-180] & 158 [130-195] \\
\hline
\end{tabular}

Crs, respiratory system compliance; Cdyn, dynamic compliance; Cstat, static compliance; Rrs, respiratory system resistance; InRes, inspiratory resistance;

ExRes, expiratory resistance

The mean static compliance in these patients with severe AVB was $0.81 \pm 0.27 \mathrm{~mL} / \mathrm{kg} / \mathrm{cmH}_{2} \mathrm{O}$ while dynamic compliance was 0.46 $\pm 0.19 \mathrm{~mL} / \mathrm{kg} / \mathrm{cmH}_{2} \mathrm{O}$.

Additionally, the respiratory mechanics variables (Cstat, Cdyn, InRes, ExRes, and auto-PEEP) were not associated with worse outcome (length of MV or length of ICU stay).

\section{Discussion}

In this study, where we evaluated the respiratory mechanics variables in the acute phase of children with severe AVB requiring $M V$, we remark the following findings: (a) Even knowing that AVB is characterized by an intense inflammatory process in the lower airways, the high values of respiratory resistance (compared with normal values of 30 to $50 \mathrm{cmH}_{2} \mathrm{O} / \mathrm{L} / \mathrm{s}$ described in the literature) observed in this sample are impressive, being $>140 \mathrm{cmH}_{2} \mathrm{O} / \mathrm{L} / \mathrm{s}$ in $50 \%$ of the infants; (b) As expected, in addition to the obstructive condition, there is a reduction in pulmonary compliance $(0.81 \mathrm{~mL} /$ $\mathrm{kg} / \mathrm{cmH}_{2} \mathrm{O}$ ); (c) Despite the intensity and the severity observed in these values, the outcome of these children was favorable (without any death).

Almost all AVB studies highlight elevated InRes and ExRes, reduced tidal volume, increased auto-PEEP, lung hyperinflation, increased FRC, and, finally, decreased respiratory compliance. 1,222,23 We believe that our study is the largest series ever published describing the impairment of respiratory mechanics in infants with severe AVB requiring MV. Quantifying such changes allows us to understand and justify certain ventilatory strategies adopted in these situations.

In our study, remarkably high values for InRes and ExRes (higher than $140 \mathrm{cmH}_{2} \mathrm{O} / \mathrm{L} / \mathrm{s}$ in $50 \%$ of cases) was observed, greater than the $33-60 \mathrm{cmH}_{2} \mathrm{O} / \mathrm{L} / \mathrm{s}$ reported in infants with normal lungs (Tables 4 and 5). ${ }^{14-17,19}$

As a consequence of this finding, elevated PIP during MV support will be required to ventilate the alveoli. Most studies of children with AVB submitted to MV report ventilatory strategies with PIP values between 25 and $32 \mathrm{cmH}_{2} \mathrm{O}$, even in children $<3$ months old..$^{23,30-32}$ The Paediatric Mechanical Ventilation Consensus Conference (PEMVECC) emphasizes that no PIP values are suggested to be used in obstructive diseases ${ }^{27}$ and ventilatory strategies should be based on the clinic and the local experience rather than consensus. ${ }^{21,22,27,32}$ Considering our findings, it could be assumed that ignoring the increased resistance of the lower airways and selecting a low PIP (disproportional to the obstruction severity), progressive alveolar derecruitment (atelectasis), and hypoxemia might occur. 
High InRes and ExRes prolong the constant time. The constant time $(\mathrm{CT}=$ compliance $\times$ resistance) determines the time at which the pressures equalize in the respiratory system, thus regulating inspiratory and expiratory times during $\mathrm{MV}^{22,33}$ In this concept, it is understood that very short inspiratory times induce hypoventilation by reducing alveolar tidal volume, while very short expiratory times induce air trapping and auto-PEEP, increasing the risk of barotrauma. ${ }^{22,33}$ Consequently, the ventilatory regime proposed for patients with high airway resistance is assumed to increase inspiratory times and, especially, prolonged expiratory times (low RR). ${ }^{78,22,33}$ Differently from what is proposed for patients with ARDS, the protocol to ventilate AVB adopted in both institutions with low $\mathrm{RR}$ requires the use of tidal volumes at the upper limit (close to $10 \mathrm{~mL} / \mathrm{kg}$ body weight), aiming at a minimally adequate minute volume for age. ${ }^{21,27,32,34}$

Infants with severe AVB could have an additional compromise, decreasing respiratory compliance (while progressing to ARDS or severe lung hyperinflation). The low Cstat values observed in infants with AVB reinforce the concept of compromise of the lung parenchyma (consolidations and atelectasis) as a consequence of the viral inflammatory process and the release of inflammatory mediators, also due to air trapping (increased FRC) association with increased resistance. ${ }^{1,2,22,35}$ We found Cstat to be slightly reduced $\left(0.81 \mathrm{~mL} / \mathrm{kg} / \mathrm{cmH}_{2} \mathrm{O}\right)$, as expected for children with predominantly lower airway obstruction and low auto-PEEP (Table 5). ${ }^{14-19}$

Among the possible limitations of this study with regard to: (a) The measurements being evaluated just in the first 48 hours of MV. This strategy aimed to evaluate the acute (and more intense) phase of the disease, where the patients would be under more critical and challenging conditions of the disease. Including patients in a late phase of the disease could result in a bias in the measurements (reversal of the inflammatory process) and induce to false conclusions. (b) There is a scarcity of reference values for respiratory mechanics parameters, for healthy and sick children, making it difficult to compare these data for infants with severe AVB on MV. This limitation could be solved just by increasing the number of studies determining such values in similar populations.

\section{ConcLusion}

Analysis of the respiratory mechanics of infants with AVB on MV showed very high InRes and ExRes levels. To overlap the airway obstruction, more aggressive ventilatory parameters are required, especially PIP. On the basis of our results, we believe that monitoring respiratory mechanics could represent a tool to guide the ventilation strategy to be adopted in patients with severe AVB. New studies in this area should also include defining respiratory mechanics values in children without pulmonary compromise, as well as studies with plateau pressure and driving pressure measurements in pediatric diseases.

\section{References}

1. Meissner HC. Viral bronchiolitis in children. N Engl J Med 2016;374(1):62-72. DOI: 10.1056/NEJMra1413456.

2. Florin TA, Plint AC, Zorc JJ. Viral bronchiolitis. Lancet 2017;389(10065):211-224. DOI: 10.1016/S0140-6736(16)30951-5.

3. Rakshi K, Couriel JM. Management of acute bronchiolitis. Arch Dis Child 1994;71(5):463-469. DOI: 10.1136/adc.71.5.463.

4. Davison C, Ventre KM, Luchetti M, Randolph AG. Efficacy of interventions for bronchiolitis in critically ill infants: a systematic review and meta-analysis. Pediatr Crit Care Med. 2004;5(5):482-489. DOI: 10.1097/01.PCC.0000128891.54799.67.

5. Ghazaly M, Nadel S. Characteristics of children admitted to intensive care with acute bronchiolitis. Eur J Pediatr 2018;177(6):913-920. DOI: 10.1007/s00431-018-3138-6.

6. Flores-González JC, Mayordomo-Colunga J, Jordan I, Miras-Veiga A, Montero-Valladares C, Olmedilla-Jodar M, et al. Prospective multicentre study on the epidemiology and current therapeutic management of severe bronchiolitis in Spain. Biomed Res Int 2017;2017:2565397. DOI: 10.1155/2017/2565397.

7. Bueno FU, Piva JP, Garcia PC, Lago PM, Einloft PR. Outcome and characteristics of infants with acute viral bronchiolitis submitted to mechanical ventilation in a Brazilian pediatric intensive care. Rev Bras Ter Intensiva 2009;21(2):174-182. DOI: 10.1590/S0103507X2009000200010.

8. Ferlini R, Pinheiro FO, Andreolio C, Carvalho PR, Piva JP. Characteristics and progression of children with acute viral bronchiolitis subjected to mechanical ventilation. Rev Bras Ter Intensiva 2016;28(1):55-61. DOI: 10.5935/0103-507X.20160003.

9. Schraufnagel DE, Seddon PC, Cheifetz IM, Frerichs I, Hall GL, Hammer $\mathrm{J}$, et al. An official American Thoracic Society/European Respiratory Society workshop report: evaluation of respiratory mechanics and function in the pediatric and neonatal intensive care units. Ann Am Thorac Soc 2016;13(1):S1-S11. DOI: 10.1513/AnnalsATS.201511-739ED.

10. Faustino EA. Concepts and monitoring of pulmonary mechanic in patients under ventilatory support in intensive care unit. Rev Bras Ter Intensiva 2007;19(2):161-169. DOI: 10.1590/S0103507X2007000200004.

11. Perez $\mathrm{M}$, Mancebo J. Monitoring ventilatory mechanics. Med Intensiva 2006;30(9):440-448. DOI: 10.1016/S0210-5691(06)74567-3.

12. Lucangelo $U$, Bernabe F, Blanch L. Respiratory mechanics derived from signals in the ventilator circuit. Respir Care 2005;50:55-65. discussion 65-7.

13. SERVO-i. 2004. Maquet Critical Care. Ventilator System V.2.0. Manual de utilização.

14. Cid JLH. Respiratory function monitoring II: compliance, airway resistance, dynamic hyperinflation, pulmonary dead-space, work of breathing. Anales de Pediatría 2003;59(3):278-285. DOI: 10.1016/ S1695-4033(03)78178-8.

15. Derish M, Hodge G, Dunn C, Ariagno R. Aerosolized albuterol improves airway reactivity in infants with acute respiratory failure from respiratory syncytial virus. Pediatr Pulmonol 1998;26(1):12-20. DOI: 10.1002/(SICI)1099-0496(199807)26:1<12::AID-PPUL4>3.0.CO;2-K.

16. Hammer J, Numa A, Newth CJ. Albuterol responsiveness in infants with respiratory failure caused by respiratory syncytial virus infection. J Pediatr 1995;127(3):485-490. DOI: 10.1016/S0022-3476(95)70088-9.

17. Almeida-Júnior AA, da Silva MT, Almeida CC, Jacomo AD, Nery BM, Ribeiro JD. Association between ventilation index and time on mechanical ventilation in infants with acute viral bronchiolitis. J Pediatr (Rio J) 2005;81(6):466-470. DOI: 10.2223/JPED.14210.

18. Cruces P, González-Dambrauskas S, Quilodrán J, Valenzuela J, Martínez J, Rivero N, et al. Respiratory mechanics in infants with severe bronchiolitis on controlled mechanical ventilation. BMC Pulm Med 2017;17(1):129. DOI: 10.1186/s12890-017-0475-6.

19. Heilitt M, Clement KC. Respiratory mechanics in the mechanically ventilated patient Rimensberger PC, Schulzke S, ed. Pediatric and neonatal mechanical ventilation. Berlin Heidelberg: Springer; 2015. pp. 293-371.

20. Mecklin $M$, Heikkila $P$, Korppi $M$. The change in management of bronchiolitis in the intensive care unit between 2000 and 2015. Eur J Pediatr 2018;177(7):1131-1137. DOI: 10.1007/s00431-018-3156-4.

21. Rotta AT, Steinhorn DM. Conventional mechanical ventilation in pediatrics. J Pediatr (Rio J) 2007;83(7):S100-S108. DOI: 10.2223/ JPED.1617.

22. Tasker RC. Bronchiolitis Rimensberger PC, ed. Pediatric and neonatal mechanical ventilation. Berlin Heidelberg: Springer; 2015. pp. 1291-1311. 
23. Rodriguez NA, Martinón TF, Martinón SJM. Ventilation in special situations. Mechanical ventilation in bronchiolitis. An Pediatr (Barc). 2003;59(4):363-366. DOI: 10.1016/S1695-4033(03)78195-8.

24. Main E, Castle R, Stocks J, James I, Hatch D. The influence of endotracheal tube leak on the assessment of respiratory function in ventilated children. Intensive Care Med 2001;27(11):1788-1797. DOI: 10.1007/s001340101105.

25. Avena MJ, Brunow W, De Carvalho WB, Beppu OS. Avaliação da mecânica respiratória e da oxigenação pré e pós-aspiração de secreção em crianças submetidas à ventilação pulmonar mecânica. Rev Assoc Med Bras 2003;49(2):156-161. DOI: 10.1590/S010442302003000200033.

26. Yehya N, Thomas NJ. Disassociating lung mechanics and oxygenation in pediatric acute respiratory distress syndrome. Crit Care Med 2017;45(7):1232-1239. DOI: 10.1097/CCM.0000000000002406.

27. Kneyber MCJ, de Luca D, Calderini E, Jarreau PH, Javouhey E, LopezHerce J, et al. Recommendations for mechanical ventilation of critically ill children from the Paediatric Mechanical Ventilation Consensus Conference (PEMVECC). Intensive Care Med 2017;43(12):1764-1780. DOI: 10.1007/s00134-017-4920-z.

28. Khemani RG, Conti D, Alonzo TA, Bart RD,3rd, Newth CJ. Effect of tidal volume in children with acute hypoxemic respiratory failure. Intensive Care Med 2009;35(8):1428-1437. DOI: 10.1007/s00134-009-1527-z.
29. Schober P, Boer C, Schwarte LA. Correlation coefficients: appropriate use and interpretation. Anesth Analg 2018;126(5):1763-1768. DOI: 10.1213/ANE. 0000000000002864 .

30. Frankel LR, Lewiston NJ, Smith DW, Stevenson DK. Clinical observations on mechanical ventilation for respiratory failure in bronchiolitis. Pediatr Pulmonol 1986;2(5):307-311. DOI: 10.1002/ ppul.1950020511.

31. Lebel MH, Gauthier M, Lacroix J, Rousseau E, Buithieu M. Respiratory failure and mechanical ventilation in severe bronchiolitis. Arch Dis Child 1989;64(10):1431-1437. DOI: 10.1136/adc.64.10.1431.

32. Lelerc F, Scalfaro P, Noizet O, Thumerelle C, Dorkenoo A, Fourier C. Mechanical ventilatory support in infants with respiratory syncytial virus infection. Pediatr Crit Care Med 2001;2(3):197-204. DOI: 10.1097/00130478-200107000-00002.

33. Shein SL, Speicher RH, Eigen H, Asthma RAT Fuhrman BP, Zimmerman JJ, ed. Pediatric critical care. Philadelphia: Elsevier; 2017. 1516-1557.

34. Pediatric Acute Lung Injury Consensus Conference G. Pediatric acute respiratory distress syndrome: consensus recommendations from the Pediatric Acute Lung Injury Consensus Conference. Pediatr Crit Care Med 2015;16(5):428-439. DOI: 10.1097/PCC.0000000000000350.

35. Kneyber MC, Zhang $H$, Slutsky AS. Ventilator-induced lung injury. Similarity and differences between children and adults. Am J Respir Crit Care Med 2014;190:258-265. DOI: 10.1164/rccm.201401-0168CP. 